\title{
The cost-effectiveness of controlling dengue in Indonesia using wMel Wolbachia released at scale: a modelling study
}

Oliver J. Brady ${ }^{1,2^{*}} \mathbb{D}$, Dinar D. Kharisma ${ }^{3}$, Nandyan N. Wilastonegoro ${ }^{4}$, Kathleen M. O'Reilly ${ }^{1,5}$, Emilie Hendrickx ${ }^{1,2}$, Leonardo S. Bastos ${ }^{1,2}$, Laith Yakob ${ }^{1,5}$ and Donald S. Shepard ${ }^{3}$

\begin{abstract}
Background: Release of virus-blocking Wolbachia-infected mosquitoes is an emerging disease control strategy that aims to control dengue and other arboviral infections. Early entomological data and modelling analyses have suggested promising outcomes, and wMel Wolbachia releases are now ongoing or planned in 12 countries. To help inform government, donor, or philanthropist decisions on scale-up beyond single city releases, we assessed this technology's cost-effectiveness under alternative programmatic options.

Methods: Using costing data from existing Wolbachia releases, previous dynamic model-based estimates of Wolbachia effectiveness, and a spatially explicit model of release and surveillance requirements, we predicted the costs and effectiveness of the ongoing programme in Yogyakarta City and three new hypothetical programmes in Yogyakarta Special Autonomous Region, Jakarta, and Bali.

Results: We predicted Wolbachia to be a highly cost-effective intervention when deployed in high-density urban areas with gross cost-effectiveness below $\$ 1500$ per DALY averted. When offsets from the health system and societal perspective were included, such programmes even became cost saving over 10-year time horizons with favourable benefit-cost ratios of 1.35 to 3.40. Sequencing Wolbachia releases over 10 years could reduce programme costs by approximately 38\% compared to simultaneous releases everywhere, but also delays the benefits. Even if unexpected challenges occurred during deployment, such as emergence of resistance in the medium-term or low effective coverage, Wolbachia would remain a cost-saving intervention.

Conclusions: Wolbachia releases in high-density urban areas are expected to be highly cost-effective and could potentially be the first cost-saving intervention for dengue. Sites with strong public health infrastructure, fiscal capacity, and community support should be prioritised.
\end{abstract}

Keywords: Dengue, Wolbachia, Mosquito, Indonesia, Cost-effectiveness analysis, Maps, Spatial, Model, Policy

\footnotetext{
* Correspondence: oliver.brady@lshtm.ac.uk

${ }^{1}$ Centre for the Mathematical Modelling of Infectious Diseases, London

School of Hygiene \& Tropical Medicine, London, UK

${ }^{2}$ Department of Infectious Disease Epidemiology, Faculty of Epidemiology

and Population Health, London School of Hygiene \& Tropical Medicine, London, UK

Full list of author information is available at the end of the article
}

(c) The Author(s). 2020 Open Access This article is licensed under a Creative Commons Attribution 4.0 International License, which permits use, sharing, adaptation, distribution and reproduction in any medium or format, as long as you give appropriate credit to the original author(s) and the source, provide a link to the Creative Commons licence, and indicate if changes were made. The images or other third party material in this article are included in the article's Creative Commons licence, unless indicated otherwise in a credit line to the material. If material is not included in the article's Creative Commons licence and your intended use is not permitted by statutory regulation or exceeds the permitted use, you will need to obtain permission directly from the copyright holder. To view a copy of this licence, visit http://creativecommons.org/licenses/by/4.0/. The Creative Commons Public Domain Dedication waiver (http://creativecommons.org/publicdomain/zero/1.0/) applies to the data made available in this article, unless otherwise stated in a credit line to the data. 


\section{Background}

The mosquito species Aedes aegypti and Ae. albopictus are responsible for transmitting a range of growing global arboviral infections. Existing vector control tools alone have been unable to sustainably control these mosquito species or the diseases they transmit [1], and a range of novel technologies are under development [2].

One such novel intervention is the release of mosquitoes infected with the intracellular bacterium Wolbachia [3]. Mosquitoes infected with Wolbachia (i) are less likely to disseminate dengue, chikungunya, Zika, and yellow fever viruses and thus are less likely to become infectious [3-5] and (ii) can suppress or replace the natural mosquito population due to fatal cytoplasmic incompatibility among Wolbachia wild-type mating pairs [3]. Wolbachia can, therefore, be used to either replace the existing mosquito population with a lower competence phenotype by releasing females or suppress existing population by releasing males. To date, 13 countries have ongoing replacement programmes at various stages of development, with 12 through the World Mosquito Programme (WMP [6]) and an independent programme in Malaysia [7]. Meanwhile, China (with Ae. albopictus) [8], Singapore [9], and the USA [10] have chosen to use suppression-based programmes due to perceived greater compatibility with their existing intensive and long-term efforts to suppress mosquito populations.

Replacement programmes with Wolbachia entail substantial initial investments to establish Wolbachia in the mosquito population through intensive releases at the beginning of the programme but potentially offer considerable long-term benefits. The replacement approach contrasts with suppression strategies with Wolbachia, sterile insect techniques, or conventional vector control tools, which likely need ongoing application. Both approaches are in the early stages of gathering entomological and epidemiological evidence of effectiveness [2]. Among these novel methods, replacement with $w \mathrm{Mel}$ Wolbachia has, arguably, the most developed evidence base so far [11] because it has demonstrated replacement in multiple sites [12, 13], durability of unaltered replacement since 2011 and cessation of autochtonous transmission in northern Australia [14, 15], reductions in reported dengue cases in observational study designs in five countries [16], and a cluster randomised trial is currently underway in Yogyakarta, Indonesia [17, 18], with epidemiological outcome results expected in late 2020.

Recent events including the 2015-2017 Latin American Zika outbreak and the record-breaking 2019 global dengue outbreak have hastened the adoption of novel Aedes control tools. Given the acute need to make decisions on adoption, mathematical models can be used to predict impact in different areas long before field data become available $[19,20]$. Pairing these epidemiological predictions with intervention cost and cost-of-illness data enables cost-effectiveness calculations that can inform decisions on Wolbachia scale-up.

One such priority setting is Indonesia, where city-wide Wolbachia releases are already planned in Yogyakarta City after the randomised trial [17]. In 2016, Indonesia launched its "Healthy Indonesia Program with Family Approach", which includes cleaning the environment and addressing communicable diseases, including malaria and dengue [21]. This programme provides encouragement and some national funding. In addition, in the Yogyakarta Special Autonomous Region (SAR), the governor has confirmed his support for novel technologies, including Wolbachia [22], suggesting support for expansion beyond Yogyakarta City.

Cost-effectiveness analyses (CEAs) have proved instrumental for the early adoption of a number of interventions, including for Aedes-borne pathogens. Fitzpatrick et al. estimated that, assuming they were 70-90\% effective, conventional Aedes suppression tools would achieve cost-effectiveness between $\$ 679$ and $\$ 1331$ per disability-adjusted life year (DALY) averted (2013 USD) [23]. The recently developed dengue vaccine, Dengvaxia ${ }^{\oplus}$, also included model-predicted CEA as part of its feasibility assessment, with predictions without serotesting of \$11-44 per DALY averted (2014 USD) [24]. Dengvaxia $^{\circ}$ has also been estimated to be highly costeffective (\$1800 per DALY, health systems perspective) or cost saving (\$-1800 per DALY, societal perspective) under the WHO's modified individual test-and-vaccinate recommendation, however with more limited overall impact (14.3\% reduction in hospitalisation) [25].

Here we use the existing Wolbachia release cost and programme data to build a model that predicts the cost of release in different environments. Using a dynamic simulation model, we synthesise cost predictions with previously published estimates of Wolbachia effectiveness [19] to assess cost-effectiveness. We then assess the sensitivity of predicted cost-effectiveness to alternative programmatic options for government or private funders to consider the next stage of scale-up of this technology.

\section{Methods}

\section{Phases of the programme}

In this analysis, we conceptually divide a potential Wolbachia replacement programme in a given city into four phases based on previous WMP operations. We do not consider the additional costs of obtaining regulatory approval in Indonesia as Wolbachia release has already been approved by the local Yogyakarta SAR government and the national government already has an active involvement in the project as part of the independent data monitoring committee. Phase 1 ("setup", 2-year duration) includes establishing insectaries and a mosquito 
colony, laboratories, site offices, local regulatory approval, hiring staff, baseline entomological surveys (including insecticide resistance monitoring), and planning and administering the programme and pre-release community engagement. Phase 2 ("release", 1-year duration) involves the release of Wolbachia mosquitoes over target areas applying the resources established during phase 1 . In phase 3 ("short-term monitoring", 3-year duration), ongoing surveillance of the mosquito and human population is conducted in the release area. Phase 4 ("longterm monitoring", 7-year duration) entails reduced entomologic monitoring as the intervention proves its reliability.

In the existing programme in Yogyakarta City, programme setup took 4 years [18]; however, this included gaining national approval, design of the cluster randomised trial, all phase 1 activities, and release in half the city. We anticipate faster setup times of subsequent programmes elsewhere in Indonesia due to the experiences and approvals gained in Yogyakarta City.

For the main analysis, we consider two speed scenarios: (i) an "accelerated" scenario, with every area conducting phases 1-4 simultaneously and independently (total programme length 13 years), and (ii) a "sequenced" scenario, in which phase 2 releases are spread over 10 years with certain centralised resources moved or reutilised across different locations (total programme length 20 years, Additional file 1, S1.1) [13, 19, 26-31].

\section{Costing Wolbachia releases (phases 1 and 2)}

We hypothesised that the main determinants of the cost of releasing Wolbachia per square kilometre $(\mathrm{km})$ were directly or indirectly related to (i) the human population density in the release area, (ii) release material (adult or egg mosquitoes), (iii) local cost of labour (as measured by country Gross Domestic Product adjusted for Purchasing Power Parity (GDP PPP) [32]), and (iv) phase of the programme. Previous Wolbachia releases have shown that higher human density areas require higher mosquito release numbers per unit area because they typically have higher natural mosquito population sizes, hence raising costs [33]. Transportation costs of Wolbachia-infected mosquito eggs are lower than for adult releases because they can be distributed in smaller containers and because the community can undertake releases; however, this can also increase community engagement costs. Adult releases require specific equipment and personnel to drive around the target area and conduct releases at pre-specified sites, but can potentially be achieved more quickly.

Data were extracted from WMP budgets for releases in Indonesia, Colombia, Sri Lanka, Australia, and Vanuatu (Additional file 1, S1.2). These data were used to fit a generalised linear regression model between cost per $\mathrm{km}^{2}$ of release area and the above covariates (Additional file 1, S1.3).

\section{Costing long-term surveillance (phases 3 and 4)}

Our estimates of the long-term monitoring costs of a Wolbachia programme (phases 3 and 4) build on a detailed budget analysis developed by the WMP for phase 2 of the programme in Yogyakarta City (Additional file $1, \mathrm{S1} .2)$. This includes a gradual reduction in monitoring intensity with corresponding budget reductions (Additional file 1, S1.1).

\section{Modelling effectiveness and cost of dengue illness averted}

Spatially explicit estimates of baseline and averted dengue cases were obtained from a recent related study [19]. In this study, spatially varying estimates of the current case burden across Indonesia were first estimated using a geospatial model that accounts for the effects of climate and socioeconomic factors in the spatial distribution of dengue burden. Within each 5 $\mathrm{km} \times 5 \mathrm{~km}$ pixel, a dynamic simulation model then estimated the long-term average force of infection required to generate the number of estimated cases. Data from laboratory vector competence experiments [29] were then used to estimate the reduction in force of infection likely to occur if Wolbachia were present in $100 \%$ (or $50 \%$ for the sensitivity analysis) of the natural mosquito population from the beginning of phase 3 of the programme (i.e. once all releases have been completed). The dynamic simulation model was then used to translate this force of infection reduction into the number of cases averted per year once a new steady endemic state has been reached which also includes indirect or spillover effects if Wolbachia coverage were less than 100\%. DALYs were calculated based on the average age of dengue cases and life expectancy at a national level in Indonesia. We assume that neither the age distribution of cases nor the costs associated changes as a result of the Wolbachia programme. Disease severity-specific (but not geographically varying) cost per case data [34] was then applied to case totals to estimate the economic costs of dengue cases and the economic benefits of averting Wolbachia relative to a baseline scenario of no action. All case counts and costs were then downscaled to $100 \mathrm{~m} \times 100$ $m$ spatial resolution to match the resolution of population datasets using bilinear interpolation.

\section{Candidate release sites}

In this analysis, we produce estimates for four candidate sites: (1) Yogyakarta City, (2) remaining areas in Yogyakarta SAR, (3) most of the special capital region of Jakarta (excluding Kepulauan Seribu [Thousand Islands] Regency), and (4) the island of Bali. 
We chose this focus based on a combination of political, economic, and epidemiologic considerations. The Yogyakarta City trial carried an ethical and political expectation to assess expanding releases across the rest of Yogyakarta City and the remainder of the SAR. The other two candidate sites, Jakarta and Bali, are two of the country's most important economic regions as commercial and tourism hubs. In epidemiologic terms, highdensity cities, such as Jakarta and Denpasar, Bali, have a disproportionately high concentration of national dengue burden [19] and island-wide releases are likely to minimise the risk of re-introduction of native Ae. aegypti populations.

Within each of these sites, not every area is expected to be covered by Wolbachia. We consider only areas with a human population density of at least 1000 people per $\mathrm{km}^{2}$ as eligible for Wolbachia releases. Previous WMP releases in Townsville and Cairns, Australia, have proven the ability to establish Wolbachia in areas approaching 1000 people per $\mathrm{km}^{2}$ (Fig. 1), but based on existing programme experience, lower population densities are likely to prove prohibitive to natural mosquito dispersal and may significantly increase the cost or lower persistence of Wolbachia mosquitoes.

\section{Time horizon, acquisition of benefits, and discounting}

As Wolbachia is an early-stage technology, we take a conservative approach to our calculation of costeffectiveness. We only assume benefits of Wolbachia persist for 10 years post completion of releases in the target area (i.e. benefits only accumulated in phases 3-4, Additional file 1, S1.1) based on the duration of continued persistence of Wolbachia releases in northern Queensland since 2011 [35].

We assumed that the number of cases averted would be the same each year. All costs and benefits are given in present value 2018 USD and were discounted at 3\% per annum [36], calculated at the end of each year. The cost of the programme was predicted using population data at $100 \mathrm{~m} \times 100 \mathrm{~m}$ resolution from Worldpop [37] assuming a programme using egg releases with Indonesia's national 2018 per capita GDP (PPP, \$12,378).

Two measures of cost-effectiveness are shown: first, from a health systems perspective (gross cost-
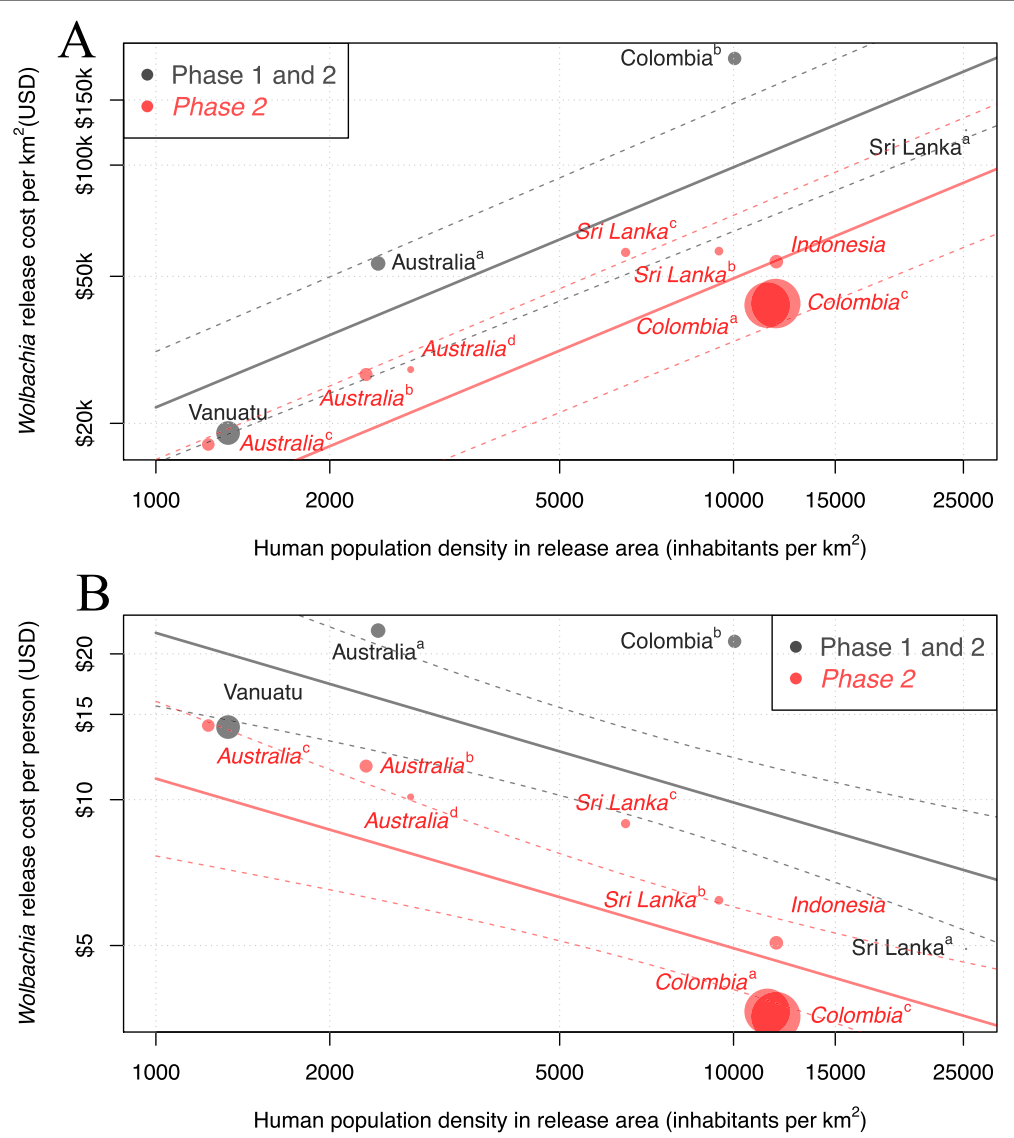

Fig. 1 The fitted relationship between human population density and projected cost of deployment of Wolbachia per $\mathrm{km}^{2}$ (a) and cost per person (b). All axes are on $\log _{10}$ scales. The cost per $\mathrm{km}^{2}$ model fit mean (solid lines) and standard error (dashed lines) for each programme phase are shown. Circle area is proportional to the size of the release area in each site 
effectiveness), where the investment cost of the programme is divided by the number of DALYs averted over the 10 years post deployment (discounted at $3 \%$ per year); second, from a societal perspective (net costeffectiveness), where offsets to direct medical treatment costs are first deducted from the programme investment costs. Benefit-cost ratios are also calculated from health systems and societal perspectives separately. We compared all scenarios against the alternative option of continuing existing dengue control measures, which primarily consist of insecticide-based vector control. We did not cost such interventions and assume that they will continue in parallel to and independently of the Wolbachia programme due to their purpose spanning vector control for a variety of different vector species.

\section{Sensitivity analyses}

To assess the sensitivity of our predictions to uncertainties in various inputs to our model, we performed a univariate sensitivity analysis based on the $2.5 \%$ and $97.5 \%$ estimates for each of the following parameters: (i) case burden, (ii) Wolbachia effectiveness, (iii) cost of Wolbachia releases, and (iv) cost per episode of dengue illness. In addition, we also examined the sensitivity of costeffectiveness to several hypothesised environmental and genetic challenges and changes that may occur as a consequence of Wolbachia introduction [38]. These include (i) low coverage (50\% vs baseline $100 \%$ coverage), (ii) releases that are initially uncompetitive with wild-type mosquito populations, and (iii) emergence of resistance (after 5 years). The cost-effectiveness of programme modifications to address these challenges is also assessed. Furthermore, we predict the cost-effectiveness of future cost-saving adaptations of the programme including (iv) reliance on passive disease surveillance (as opposed to continued entomological surveillance in phase 4 of the programme) and (v) generic innovations, efficiencies, and economies of scale that reduce the cost base of the programme by $50 \%$. Further details on the rationale for these scenarios and their parameterisation are available in Additional file 1, S1.4. All analyses were performed in $\mathrm{R}$ version 3.6.1. with all code publicly available in the following GitHub repository (https://github. com/obrady/Wolbachia_CE/tree/V1). This manuscript conforms to the Consolidated Health Economic Evaluation Reporting Standards (CHEERS) checklist which can be found in Additional file 2 .

\section{Results}

\section{Wolbachia programme costs}

The results of our model to predict the cost of releasing Wolbachia mosquitoes in new areas using existing programme budgets are shown in Fig. 1. This model identified human population density and programme phase as significant covariates of programme cost per $\mathrm{km}^{2}$ of release area $(p=0.003$ and $p=0.026$ respectively, two-sided $t$ test, Additional file 1, S1.3). Release material (eggs or adult mosquitoes) or national GDP per capita (as a proxy for local labour costs) were not found to be significant ( $p=0.98$ and 0.31 respectively) but were retained in the final model due to limited between site variance. Models with the response variable of cost per $\mathrm{km}^{2}$ gave superior cost data fit to models with a response variable of cost per person, so were used throughout (Additional file 1, S1.3).

Each of the four candidate sites differs in size and human population density, comprising a small city (Yogyakarta City), a large city (Jakarta), and two moderate-size urban-rural mixes (Yogyakarta SAR and Bali, Table 1). Because we assume Wolbachia to be suitable only in areas with density greater than 1000 people per $\mathrm{km}^{2}$, only $24.8 \%$ and $14.9 \%$ of the land area in Yogyakarta SAR and Bali are eligible for Wolbachia release, compared to $100 \%$ in urban areas, although these areas do still contain the majority of people (Table 1).

The estimated cost of an accelerated (10-year) Wolbachia programme ranges from $\$ 5.8$ million in Yogyakarta City to \$133.3 million in Jakarta (present value 2018 USD, Table 1). While the urban sites have a smaller release area than their urban-rural mix counterparts, the cost per $\mathrm{km}^{2}$ of releasing in high-density areas is much higher (Fig. 1); however, because more people are covered, urban areas lead to more favourable cost per person covered ( $\sim 12$ vs $\$ 14-21$, Table 1$)$.

Conducting releases over a longer sequenced programme (total programme length 20 years vs 13 years) can reduce overall costs by $11-38 \%$ (Table 1 ), but also delay benefits (Fig. 2). In this analysis, we assume 10 years of benefits for each area in which Wolbachia mosquitoes are released because there is currently substantial uncertainty over costs and effectiveness beyond 10 years (Fig. 2). Should Wolbachia prove more durable than this, accelerated programmes and their quicker acquisition of benefits would become more preferable relative to sequenced programmes; however, the challenges of their greater upfront costs would remain.

\section{Benefits}

Combining health systems costs and societal costs (lost wages due to work absences attributable to sickness and the value of life lost due to premature death), Indonesia's national economic burden of dengue in 2017 has been estimated at $\$ 681.26$ million [34], with costs due to hospitalised non-fatal cases (44.7\%), fatal cases (44.3\%), ambulatory non-fatal cases (5.7\%), and non-medical cases (5.3\%) [34]. We predict substantial reductions in dengue case and economic burden in all sites. As estimated in previous work [19], long-term average percentage 
Table 1 Baseline characteristics and model-predicted release costs for current and future release areas. Prices are in present value 2018 USD. Figures in brackets represent 95\% uncertainty intervals. All costs are discounted at 3\% per annum. Accel. denotes accelerated; Seq. denotes sequenced

\begin{tabular}{|c|c|c|c|c|c|c|c|}
\hline & Existing area & Candidate sites & & & & & \\
\hline & Yogyakarta City & Yogyakarta SAR & & Jakarta & & Bali & \\
\hline Residents (millions) & 0.46 & 3.24 & & 11.19 & & 4.08 & \\
\hline $\begin{array}{l}\text { Percentage of people } \\
\text { covered by Wolbachia }\end{array}$ & 100 & 65.9 & & 100 & & 59.7 & \\
\hline Area $\left(\mathrm{km}^{2}\right)$ & 37.24 & 3666.21 & & 764.48 & & 6476.03 & \\
\hline $\begin{array}{l}\text { Percentage of area } \\
\text { eligible for Wolbachia }\end{array}$ & 100 & 24.8 & & 99.9 & & 14.9 & \\
\hline $\begin{array}{l}\text { Density in covered } \\
\text { area (persons } / \mathrm{km}^{2} \text { ) }\end{array}$ & 12,351 & 2352 & & 14,647 & & 2532 & \\
\hline \multirow{2}{*}{$\begin{array}{l}\text { Total cost } \\
\text { (US\$ millions) }\end{array}$} & Accel. & Seq. & Accel. & Seq. & Accel. & Seq. & Accel. \\
\hline & $\begin{array}{l}5.84 \\
(5.81-5.87)\end{array}$ & $\begin{array}{l}27.41 \\
(27.37-27.45)\end{array}$ & $\begin{array}{l}30.68 \\
(30.65-30.73)\end{array}$ & $\begin{array}{l}83.33 \\
(83.22-83.49)\end{array}$ & $\begin{array}{l}133.30 \\
(133.14-133.49)\end{array}$ & $\begin{array}{l}34.88 \\
(34.81-34.93)\end{array}$ & $\begin{array}{l}51.66 \\
(51.57-51.72)\end{array}$ \\
\hline Cost per person covered & $\begin{array}{l}12.70 \\
(12.63-12.77)\end{array}$ & $\begin{array}{l}12.83 \\
(12.81-12.85)\end{array}$ & $\begin{array}{l}14.36 \\
(14.35-14.38)\end{array}$ & $\begin{array}{l}7.45 \\
(7.44-7.46)\end{array}$ & $\begin{array}{l}11.92 \\
(11.90-11.93)\end{array}$ & $\begin{array}{l}14.32 \\
(14.29-14.34)\end{array}$ & $\begin{array}{l}21.21 \\
(21.17-21.23)\end{array}$ \\
\hline
\end{tabular}

reductions are likely to be highest in low transmission intensity environments $(87.2 \%$ reduction in Yogyakarta SAR vs $65.7 \%$ reduction in Jakarta, Table 2). However, because Wolbachia programmes can achieve higher coverage in dense high transmission intensity cities, the percentage reduction across the whole site area becomes more favourable $(65.7 \%$ in Jakarta vs $59.1 \%$ in Yogyakarta SAR and $52.4 \%$ in Bali). Medium transmission intensity high-density cities, such as Yogyakarta
City, are likely to see the highest percentage reduction and may even see elimination (94.4\%, 95\% uncertainty interval [95UI] 36.5-100\%).

The annual cost savings of averting these cases are substantial, ranging from $\$ 980,000$ (95UI $\$ 350,000-\$ 2$, 170,000) in Yogyakarta City to $\$ 27.1$ million (95UI \$10.58-\$49.35 million) in Jakarta. As estimated in previous work [34], these cost savings are divided approximately equally between medical costs and societal costs.
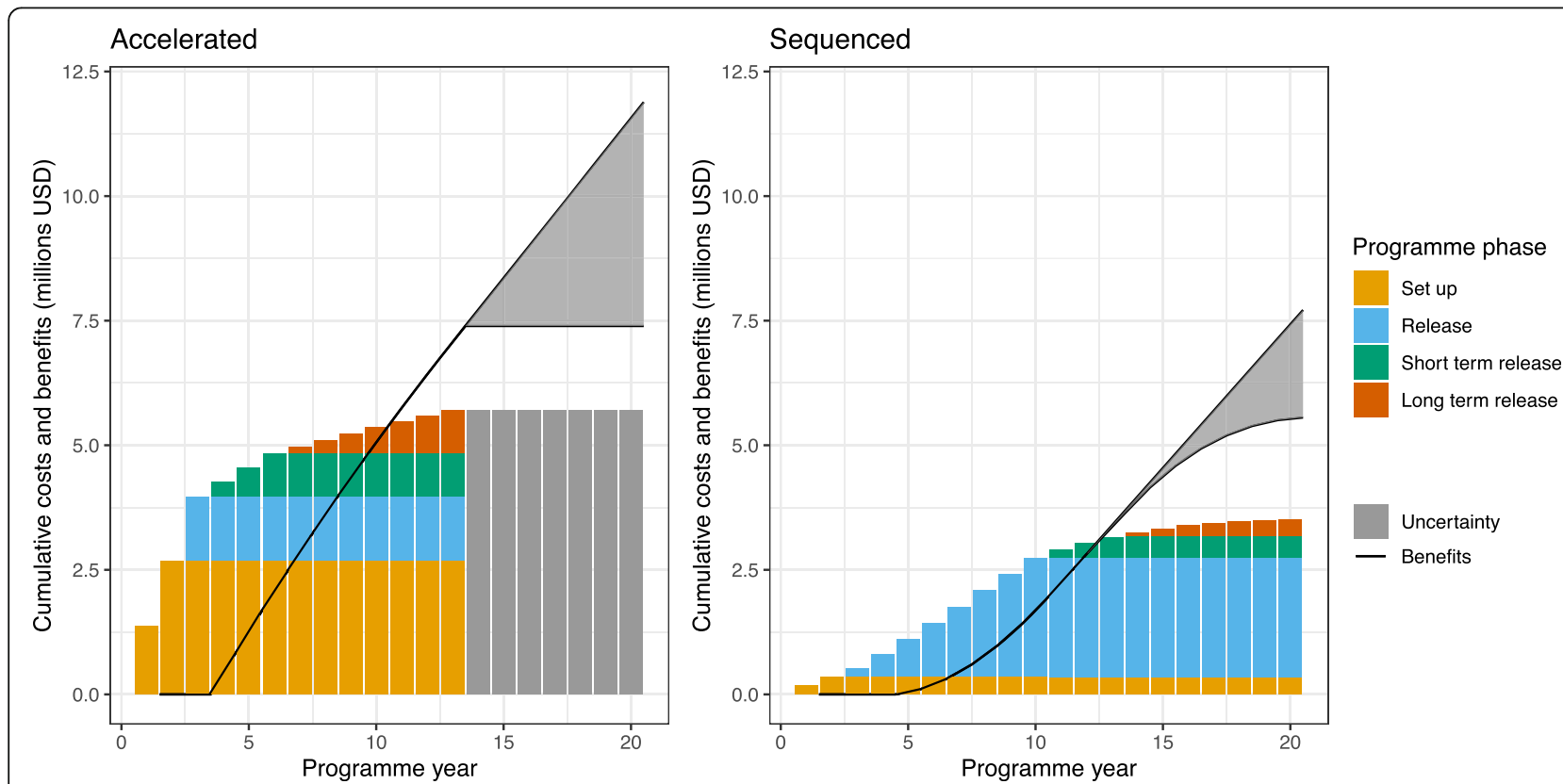

Fig. 2 Distribution of cumulative costs and savings over time in an accelerated (3 years, left panel) and sequenced (10 years, right panel) roll out in Yogyakarta City in 2018 USD. Uncertainty represents uncertainty in programme cost and intervention effectiveness beyond the 10-year postrelease time horizon used in this analysis. All costs and benefits are in present-day value 2018 USD discounted at 3\% per annum 
Table 2 Predicted per year benefits of Wolbachia programmes in four sites. Only eligible areas (at least 1000 people per $\mathrm{km}^{2}$ ) receive treatment. All costs are in 2018 US dollars and are not discounted. Figures in brackets represent 95\% uncertainty intervals

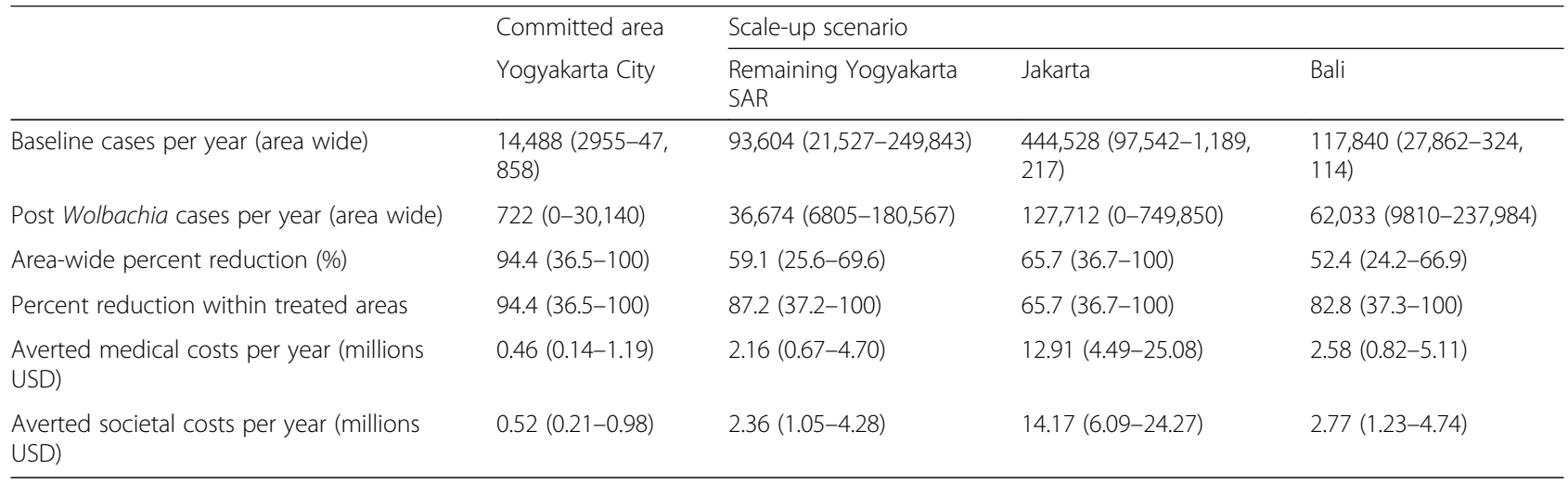

\section{Cost-effectiveness}

Due to the heterogeneous nature of risk and cost, estimated cost-effectiveness values are spatially variable (Table 3, Fig. 3). Generally, cost-effectiveness is most favourable in high-density urban environments with gross cost-effectiveness (cost of averted disease cases not included) reaching as favourable as $\$ 1100$ per DALY averted in specific places (Fig. 3c), especially in a sequenced programme (Table 3). Although the overall gross cost-effectiveness of the projected programmes in Yogyakarta SAR and Bali are less favourable than their urban counterparts (Table 3), there are many sub-areas within these sites where Wolbachia programmes could have equally as favourable cost-effectiveness (Fig. 3b, d). This is most pronounced for the Yogyakarta SAR scenario where the surrounding urban areas of Sleman, Bantul, and the isolated towns of Sentol and Wonosari are predicted to be highly cost-effective $(<\$ 1700 / \mathrm{DALY})$ while many rural areas are less favourable. We even predict some of these towns in Yogyakarta SAR to be more cost-effective than Yogyakarta City; however, this result occurs only because we assume that the core resources (e.g. laboratory and rearing facilities) that have already been paid for and developed for the existing Wolbachia programme in Yogyakarta City can be reused for the surrounding areas in Yogyakarta SAR.

When the health sector and societal costs of averted cases are deducted from the original programme investment, Wolbachia becomes a cost-saving intervention in cities and a highly cost-effective intervention elsewhere (Table 3 and Fig. 4a). One dollar invested in Wolbachia can return between $\$ 1.35$ and $\$ 3.40$ (95UI $\$ 0.17-\$ 9.67$ ) in medical and societal benefits depending on where the programme takes place (Fig. 4a). In Jakarta, the medical benefits alone are predicted to outweigh the cost of investment in Wolbachia (Fig. 4a).

\section{Sensitivity and uncertainty}

Our prediction that Wolbachia is cost saving is robust to a reasonable range of parameter values (Fig. 4b). In a univariate sensitivity analysis of the 2.5 and 97.5 percentiles of the true parameter value, only a low value of the baseline burden of dengue is sufficient to prevent Wolbachia from becoming cost saving, and even then, the

Table 3 Predicted cost-effectiveness of Wolbachia at the end of the programme. Accelerated and sequenced programmes correspond to completing roll out in 3 and 10 years, respectively. Only eligible areas (at least 1000 people per $\mathrm{km}^{2}$ ) receive treatment. All costs are in present value 2018 US dollars. All costs and benefits are discounted at a rate of 3\% per annum. Net costs include cost offsets for medical and societal benefits from averted cases. Figures in brackets represent 95\% uncertainty intervals

\begin{tabular}{|c|c|c|c|c|}
\hline & \multirow{2}{*}{$\begin{array}{l}\text { Committed area } \\
\text { Yogyakarta City }\end{array}$} & \multicolumn{3}{|l|}{ Scale-up scenario } \\
\hline & & Remaining Yogyakarta SAR & Jakarta & Bali \\
\hline & & Accelerated introduction & & \\
\hline Gross $\$ / D A L Y$ averted & $\$ 1831(892-4522)$ & $\$ 2133(1048-4953)$ & $\$ 1566(857-3244)$ & \$ 2996 (1599-6778) \\
\hline \multirow{2}{*}{$\begin{array}{l}\text { Net } \$ / D A L Y \text { averted (including averted } \\
\text { medical and societal costs) }\end{array}$} & $\$-543(-1419-1976)$ & $\$-242(-1275-2438)$ & $\$-839(-1500-731)$ & $\$ 671(-719-4219)$ \\
\hline & & Sequenced introduction & & \\
\hline Gross \$/DALY averted & $\$ 1519(737-3732)$ & $\$ 2168(1064-5042)$ & $\$ 1111(611-2307)$ & $\$ 2366(1264-5379)$ \\
\hline $\begin{array}{l}\text { Net \$/DALY averted (including health } \\
\text { sector and societal costs) }\end{array}$ & $\$-862(-1572-1185)$ & $\$-210(-1258-2528)$ & $\$-1280(-1772--207)$ & $\$ 64(-1050-2834)$ \\
\hline
\end{tabular}




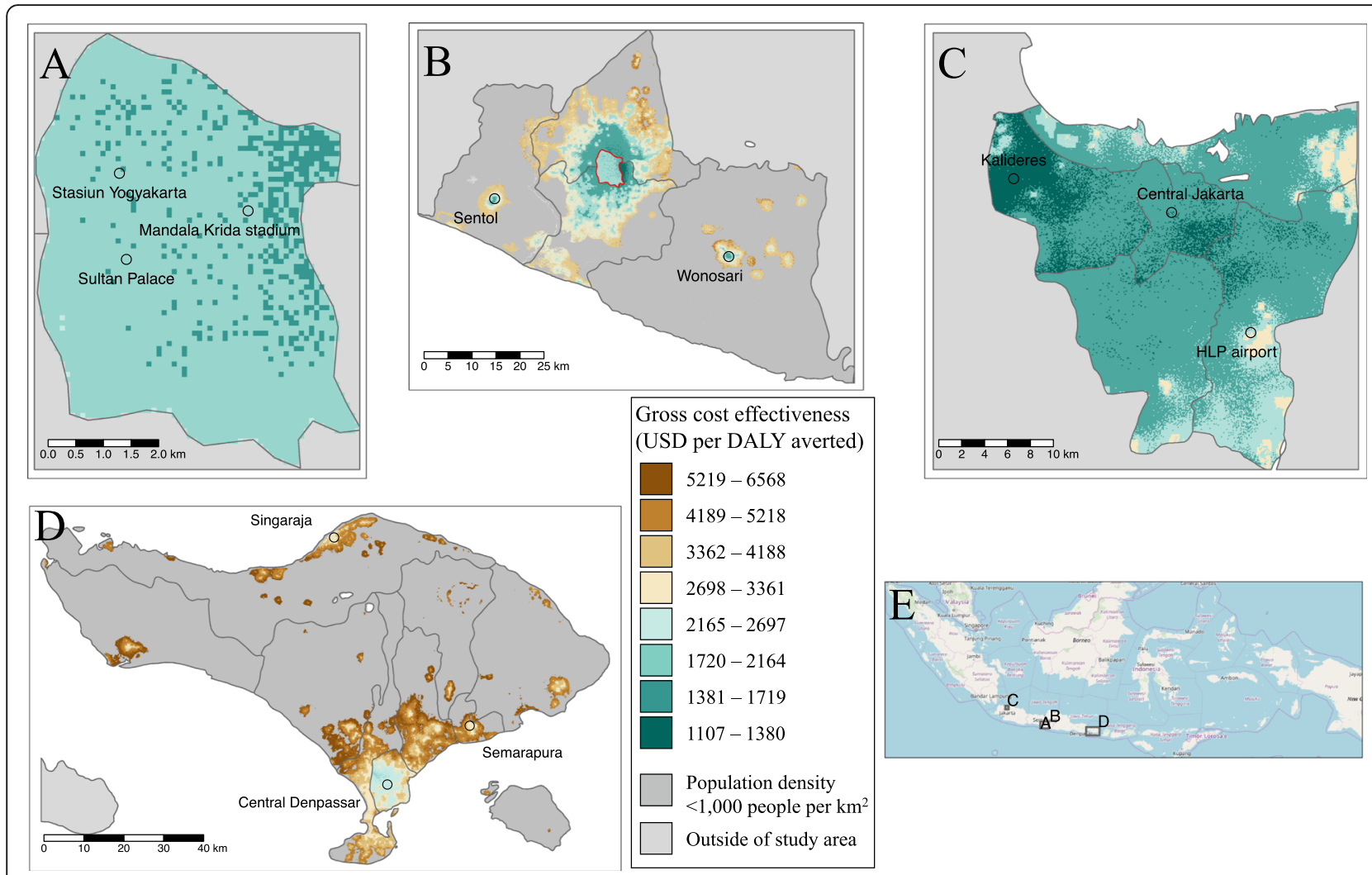

Fig. 3 Maps of the gross cost-effectiveness of accelerated Wolbachia releases in Yogyakarta City (a), Yogyakarta SAR (b), Jakarta (c), and Bali (d). Cost-effectiveness is measured in present value 2018 USD per disability-adjusted life year (DALY) averted with green areas being most favourable. Select areas of interest and the national orientation of these sites (e) are shown for reference; more detailed background maps are available in Additional file 1, S1.6. Site A falls within site B and is marked in a red outline

programme is still highly cost-effective (\$1652/DALY, sequenced programme in Yogyakarta City, societal perspective). Parameters for the cost of the programme, cost per case, and efficacy of the intervention were less critical for overall cost-effectiveness than baseline burden due to the higher uncertainty in the true burden of dengue.

Programmes are even predicted to be cost saving if substantial challenges occur during deployment. If only $50 \%$ coverage were reached in the target area, resistance emerges after 5 years or released mosquitoes are initially uncompetitive with wild-type mosquitoes, benefit-cost ratios remain above 1 (Fig. 4c, societal perspective). Furthermore, if these events do occur, cost-effectiveness of the programme can still be recovered by addressing these threats (Fig. 4c and Additional file 1, S1.5). As Wolbachia programmes become more proven over time, it is expected that relaxed surveillance (relying on passive disease monitoring), innovations, and economies of scale will reduce the cost of deployment. These have the potential to increase the benefit-cost ratio by as much as $47 \%$, as long as they do not come at the expense of avoiding to detect more damaging failures of the programme (Fig. 4c).

\section{Discussion}

Here we use existing cost data to build a programmatic model for wMel Wolbachia. By applying this model in Indonesia, we show that this novel technology can be an economically advantageous intervention for dengue control and predict under what circumstances it might be most cost-effective. Cost-effectiveness of Wolbachia is predicted to be most favourable in dense cities where a high concentration of people and dengue incidence allow the high investment costs of Wolbachia to be quickly offset. In such areas, programmes can become cost saving, or dominant over existing practices, with each $\$ 1$ invested in a Wolbachia programme repaying $\$ 1.35-\$ 3.40$ in averted medical and society costs of illness. Finally, we show that Wolbachia can also be costeffective in suburban and rural areas, particularly if they can utilise programme infrastructure from nearby urban areas. This is particularly relevant for the existing $\mathrm{Wol}$ bachia programme in Yogyakarta City and suggests that expansion to nearby areas in Sleman and Bantul in Yogyakarta SAR should be considered.

Assessing the cost-effectiveness of novel rear and release vector control strategies is important because of 

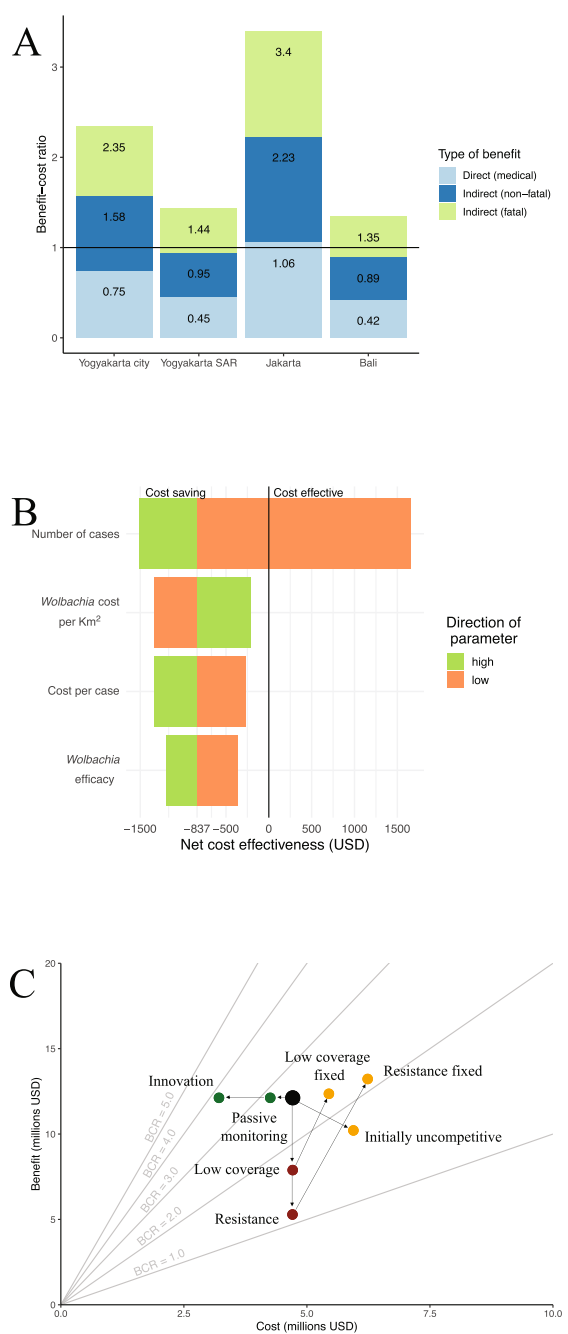

Fig. 4 Benefit-cost ratios and their sensitivity. a The predicted benefitcost ratios of a sequenced release programme in each site disaggregated by the type of benefit. A benefit-cost ratio of 1.0 or higher indicates cost saving. $\mathbf{b}$ Sensitivity of cost-effectiveness of a sequenced release in Yogyakarta City if the $2.5 \%$ value (orange) or $97.5 \%$ value (green) were used as opposed to the median value for selected parameters. Net cost-effectiveness is in 2018 present-day value USD per disability-adjusted life year averted and includes offsets from health sector and societal perspectives. $\mathbf{c}$ Sensitivity of benefitcost ratios (BCRs) to future challenges or changes to a sequenced release in Yogyakarta City. Green dots show potential cost-saving measures, red dots unaddressed challenges to the programme, and yellow dots addressed challenges to the programme. Dots above the $B C R=1.0$ line are cost saving from the societal perspective

their high upfront costs but potentially long-term benefits. This makes the cost-effectiveness dynamics of $w \mathrm{Mel}$ Wolbachia more similar to mass vaccination than conventional vector control. Like vaccination, this makes cost-effectiveness of Wolbachia sensitive to the time horizon of the evaluation. wMel Wolbachia has been robustly established in Cairns, Australia, since early 2011 [35], hence our assumed 10-year benefit time horizon.
More research is required to understand the sustainability of Wolbachia replacement in dengue-endemic countries with more complex Aedes population genetics and higher virus and mosquito importation rates from outside areas [39].

A number of previous studies have attempted to estimate the cost-effectiveness of vector control interventions for dengue [23, 40-43]. The methods used tend to fall into one of two approaches: field trials or modelbased assessments. Experimental and observational control trials have been used to estimate cost-effectiveness (per DALY averted) for larvicides in Cambodia (\$313) [40], community clear up campaigns (\$3953) and ultralow volume spraying (\$4472) in Mexico [42], and an integrated package of vector control interventions in Sri Lanka (\$98) [43]. Short-term control trials with disease endpoints are likely to overestimate effectiveness due to the effects of heard immunity and may mean interventions delay rather than avert disease.

In response to this, model-based cost-effectiveness evaluations can be used to give a more accurate estimate of long-term effectiveness of a particular intervention. However, because long-term effectiveness is not easily measurable, such modelling studies often have to assume a range of plausible efficacies with variable theoretical support. Modelling studies have suggested larval control (\$615-1267/DALY) [41], and more generic packages of vector control (\$679-1907/DALY) [23] can also be costeffective depending on true effectiveness. Finally, several models have predicted the cost-effectiveness of dengue vaccines $[25,44]$. The cost-effectiveness of WHO's recommended test-and-vaccinate strategy in Indonesia in 2015 was 0.8 to 0.6 times the per capita GDP (i.e. $\$ 2700$ and \$2000) if dengue seroprevalence rates at age 9 were $50 \%$ and $70 \%$, respectively [25]. Despite vaccination having a less favourable predicted cost-effectiveness than Wolbachia, it is likely both vaccine and vector control will be necessary to achieve control in the highest transmission areas. Further work is needed to understand how the economics of combinations of interventions vary across transmission strata.

Given that Wolbachia is also not predicted to fully eliminate dengue virus transmission in highly endemic settings $[19,20]$ and given that many countries already have established dengue control programmes, there is a pressing need to understand how Wolbachia interacts with other types of vector control and how the optimal package of interventions may change in different environments. Modelling and mapping techniques are critical for such investigations due to the impracticality of conducting field trials among the many combinations of different interventions $[45,46]$.

Our approach to assessing the cost-effectiveness of Wolbachia combines the best currently available 
evidence for the effect of Wolbachia on transmission [29] with a long-term mathematical model [19] to overcome limitations of both of these approaches. This work aims to provide an evidence-based first estimate that gives quantitative support behind the decision to invest large sums of money in an intervention that is likely to have deferred but substantial benefits. Using modelbased estimates of the true case and economic burden of dengue [19, 34] in Indonesia was a critical step in our approach. Using reported case data would have significantly underestimated the cost-effectiveness of Wolbachia, and more research is needed to understand, adjust for, and ultimately fill gaps in disease surveillance [47].

This analysis was subject to a number of limitations. First, our model did not consider logistical constraints that may exist in releasing Wolbachia-infected mosquitoes at this scale. The largest current planned releases of Wolbachia mosquitoes are in Medellin Colombia where a sequenced programme will cover a combined 1.7 million people over $151 \mathrm{~km}^{2}$. Reaching high coverage of Wolbachia for Jakarta's 11 million residents and 764$\mathrm{km}^{2}$ land area, particularly over a 3-year accelerated campaign, may not be logistically feasible. New approaches to large-scale community engagement and recruitment of release teams need to be developed. There may also be constraints on the portability of assets, such as centralised distribution of mosquitoes or laboratory testing, across areas as wide as Bali that we did not consider. Second, cost data for existing Wolbachia releases were based on budgeted costs; actual costs may differ by the end of the programme. Third, our analysis only included the effects of Wolbachia on dengue, despite showing strong protective effects against a range of other arboviral diseases [3-5]. Given chikungunya is also ubiquitous in Indonesia [48], our predictions may underestimate the cost-effectiveness of Wolbachia. Fourth, we may underrepresent sub-national heterogeneity in the costs of dengue cases and in the cost of a Wolbachia programme. While both of these variables were informed by other data from different countries and were reasonably extrapolated across Indonesia using geospatial mapping approaches, our Indonesian data from both parameters came only from Yogyakarta city, the capital of a region with a per capita GDP 39\% below the Indonesian average. More data on cost of illness and cost of the intervention in other parts of Indonesia would strengthen the case for national decision-making [49]. Finally, it should be mentioned that the costeffectiveness analysis presented here is intended to form one part of the wider evidence base on whether or where Wolbachia should be scaled up. To date, successful Wolbachia programmes have been underpinned by sustained and robust engagement with both the community and local stakeholders $[14,50]$. In this analysis, we make clear assumptions about the success of establishing $\mathrm{Wol}$ bachia in a target area, but clearly an assessment of feasibility of this aim is a necessary precursor to assessments of cost-effectiveness.

The biggest strength of our analysis is the use of comprehensive, detailed spatiotemporal models that incorporate the latest projections of dengue case and economic burden, and the likely impact Wolbachia could have when deployed at scale. Given Wolbachia is an earlystage novel intervention, we have also endeavoured to include the broad range of uncertainty that exists in each of these inputs and assess their impact overall costeffectiveness. Such comparisons are important if the high upfront investment costs of Wolbachia are to be justified, and these results can be used as part of the evidence base in the decision to accelerate scale-up of $\mathrm{Wol}$ bachia to address the growing needs of arboviral control.

\section{Conclusions}

In conclusion, in this study, we show that Wolbachia has the potential to be a highly cost-effective and even cost-saving intervention, especially if targeted to highdensity cities where the burden of dengue is concentrated. These findings are largely robust to uncertainties in the long-term performance of Wolbachia, but further longitudinal field data with epidemiological outcome measures are required to validate these predictions and assess how cost-effectiveness changes when combined with other vector control interventions and vaccines.

\section{Supplementary information}

Supplementary information accompanies this paper at https://doi.org/10. 1186/s12916-020-01638-2.

Additional file 1. Additional information on the methods and results of the main manuscript. Includes further details on the timing of different phases in different scenarios (S1.1), cost of release data (S1.2), more detailed methods on the cost of release model and its fit (S1.3), the parameter values and rational for long-term cost reductions (S1.4), further background on specific challenges to the establishing Wolbachia and how they can be overcome (S1.5) and maps of cost effectiveness with more detailed Ordinance survey base maps (S1.6).

Additional file 2. The ISPOR Consolidated Health Economic Evaluation Reporting Standards (CHEERS) checklist.

\section{Abbreviations \\ CEA: Cost-effectiveness analysis; DALY: Disability-adjusted life year; GDP: Gross Domestic Product; PPP: Purchasing Power Parity; SAR: Special Autonomous Region; USD: United States Dollar; WHO: World Health Organization; WMP: World Mosquito Programme}

\section{Acknowledgements}

The design of the study was developed independently, but benefitted from a series of in-depth discussions with representatives from WMP global headquarters in Melbourne, Australia (including Cameron Simmons, Scott O'Neil and Reynold Dias), and field site coordinators from UGM, Yogyakarta City, Indonesia (including Adi Uterini). The investigators had access to all the data and had final responsibility for the decision to submit for publication. 


\section{Authors' contributions}

$\mathrm{OJB}$ and DSS conceived and designed the study. KMO, OJB, EH, DDK, NNW and LSB analysed the data. OJB, DDK, NNW, KMO, EH, LSB, LY, and DSS drafted and revised the manuscript. The authors read and approved the final manuscript.

\section{Funding}

OJB was funded by a Sir Henry Wellcome Fellowship funded by the Wellcome Trust (206471/Z/17/Z) and a grant from the Bill and Melinda Gates Foundation (OP1183567) which also supports KMO. NNW, DDK, and DSS are funded by a grant from the Bill \& Melinda Gates Foundation (OPP1 187889). The funders had no role in the study design, data collection and analysis, decision to publish, or preparation of the manuscript.

\section{Availability of data and materials}

All data used in this analysis is publicly available and can be accessed in the related paper O'Reilly et al. [19] or in Additional file 1 of this paper. All code to reproduce our analysis is publicly available in the following GitHub repository: https://github.com/obrady/Wolbachia_CE/tree/V1.

\section{Ethics approval and consent to participate}

Not applicable

\section{Consent for publication}

Not applicable

\section{Competing interests}

The authors declare that they have no competing interests.

\section{Author details}

${ }^{1}$ Centre for the Mathematical Modelling of Infectious Diseases, London School of Hygiene \& Tropical Medicine, London, UK. ${ }^{2}$ Department of Infectious Disease Epidemiology, Faculty of Epidemiology and Population Health, London School of Hygiene \& Tropical Medicine, London, UK. ${ }^{3}$ Heller School for Social Policy and Management, Brandeis University." Waltham, MA, USA. ${ }^{4}$ Faculty of Medicine, Public Health and Nursing, Gadjah Mada University, Yogyakarta, Indonesia. ${ }^{5}$ Department of Disease Control, Faculty of Infectious Tropical Diseases, London School of Hygiene \& Tropical Medicine, London, UK.

\section{Received: 11 January 2020 Accepted: 15 May 2020}

Published online: 09 July 2020

\section{References}

1. Bowman LR, Donegan S, McCall PJ. Is dengue vector control deficient in effectiveness or evidence?: systematic review and meta-analysis. PLoS Negl Trop Dis. 2016:10:e0004551.

2. Ritchie SA, Staunton KM. Reflections from an old Queenslander: can rear and release strategies be the next great era of vector control? Proc R Soc B Biol Sci. 2019;286:20190973.

3. Walker T, Johnson PH, Moreira LA, Iturbe-Ormaetxe I, Frentiu FD, McMeniman CJ, et al. The WMel Wolbachia strain blocks dengue and invades caged Aedes aegypti populations. Nature. 2011;476:450-3.

4. Aliota MT, Peinado SA, Velez ID, Osorio JE. The wMel strain of Wolbachia reduces transmission of Zika virus by Aedes aegypti. Sci Rep. 2016;6:28792.

5. van den Hurk AF, Hall-Mendelin S, Pyke AT, Frentiu FD, McElroy K, Day A, et al. Impact of Wolbachia on infection with chikungunya and yellow fever viruses in the mosquito vector Aedes aegypti. PLoS Negl Trop Dis. 2012;6: e1892.

6. WMP. World Mosquito Programme. https://www.worldmosquitoprogram. org. Accessed 14 May 2020

7. Nazni WA, Hoffmann AA, Afizah AN, Cheong YL, Mancini MV, Golding N, et al. Establishment of Wolbachia strain WAlbB in Malaysian populations of Aedes aegypti for dengue control. Curr Biol. 2019;29:1-8.

8. Zheng X, Zhang D, Li Y, Yang C, Wu Y, Liang $X$, et al. Incompatible and sterile insect techniques combined eliminate mosquitoes. Nature. 2019;572:56-61.

9. Singapore National Environment Agency. Project Wolbachia Singapore. 2019. https://www.nea.gov.sg/corporate-functions/resources/research/ wolbachia-aedes-mosquito-suppression-strategy/project-wolbachiasingapore. Accessed 30 Sept 2019.
10. Mains JW, Kelly PH, Dobson KL, Petrie WD, Dobson SL. Localized control of Aedes aegypti (Diptera: Culicidae) in Miami, FL, via inundative releases of Wolbachia-infected male mosquitoes. J Med Entomol. 2019;56:1296-303.

11. Flores HA, O'Neill SL. Controlling vector-borne diseases by releasing modified mosquitoes. Nat Rev Microbiol. 2018;16:508-18.

12. Schmidt TL, Barton NH, Rašić G, Turley AP, Montgomery BL, Iturbe-Ormaetxe I, et al. Local introduction and heterogeneous spatial spread of denguesuppressing Wolbachia through an urban population of Aedes aegypti. PLoS Biol. 2017;15:e2001894

13. Garcia G de A, Sylvestre G, Aguiar R, da Costa GB, Martins AJ, Lima JBP, et al. Matching the genetics of released and local Aedes aegypti populations is critical to assure Wolbachia invasion. PLoS Negl Trop Dis. 2019;13:e0007023.

14. O'Neill SL, Ryan PA, Turley AP, Wilson G, Retzki K, Iturbe-Ormaetxe I, et al. Scaled deployment of Wolbachia to protect the community from dengue and other Aedes transmitted arboviruses. Gates Open Res. 2018;2:36

15. Ryan PA, Turley AP, Wilson G, Hurst TP, Retzki K, Brown-Kenyon J, et al. Establishment of wMel Wolbachia in Aedes aegypti mosquitoes and reduction of local dengue transmission in Cairns and surrounding locations in northern Queensland. Australia Gates Open Res. 2020;3:1547.

16. Anders KL. Growing evidence that the World Mosquito Program's Wolbachia method reduces dengue transmission. In: 68th Annual Meeting of the American Society of Tropical Medicine and Hygiene. National Harbour, MD; 2019.

17. Anders $\mathrm{KL}$, Indriani $\mathrm{C}$, Ahmad RA, Tantowijoyo W, Arguni $\mathrm{E}$, Andari B, et al. The AWED trial (applying Wolbachia to eliminate dengue) to assess the efficacy of Wolbachia-infected mosquito deployments to reduce dengue incidence in Yogyakarta, Indonesia: study protocol for a cluster randomised controlled trial. Trials. 2018;19:302.

18. Tantowijoyo W, Andari B, Arguni E, Budiwati N, Nurhayati I, Fitriana I, et al. Stable establishment of wMel Wolbachia in Aedes aegypti populations in Yogyakarta, Indonesia. PLoS Negl Trop Dis. 2020;14:e0008157.

19. O'Reilly KM, Hendrickx E, Kharisma DD, Wilastonegoro NN, Carrington LB, Elyazar IRF, et al. Estimating the burden of dengue and the impact of release of wMel Wolbachia-infected mosquitoes in Indonesia: a modelling study. BMC Med. 2019;17:172.

20. Ferguson NM, Kien DTH, Clapham H, Aguas R, Trung VT, Chau TNB, et al. Modeling the impact on virus transmission of Wolbachia-mediated blocking of dengue virus infection of Aedes aegypti. Sci Transl Med. 2015;7:279ra37.

21. General Secretary of the Ministry of Health of Indonesia. Guidelines for Indonesian health program with family approach (Pedoman umum program Indonesia sehat dengan pendekatan keluarga). Jakarta: Kementerian Kesehatan Republik Indonesia; 2016.

22. World Mosquito Program Indonesia. Research as the evidence of deployment impact of Aedes aegypti with Wolbachia to reduce the dengue transmission in Yogyakarta City (Riset untuk membuktikan dampak Pelepasan Aedes aegypti ber-Wolbachia berskala luas pada penurun. Yogyakarta, Indonesia; 2016.

23. Fitzpatrick C, Haines A, Bangert M, Farlow A, Hemingway J, Velayudhan R. An economic evaluation of vector control in the age of a dengue vaccine. PLoS Negl Trop Dis. 2017;11:e0005785.

24. Flasche S, Jit M, Rodríguez-Barraquer I, Coudeville L, Recker M, Koelle K, et al. The long-term safety, public health impact, and cost-effectiveness of routine vaccination with a recombinant, live-attenuated dengue vaccine (Dengvaxia): a model comparison study. PLoS Med. 2016;13:e1002181.

25. Coudeville L, Baurin N, Shepard DS. The potential impact of dengue vaccination with, and without, pre-vaccination screening. Vaccine. 2020;38 1363-9.

26. Ross PA, Endersby NM, Hoffmann AA. Costs of three Wolbachia infections on the survival of Aedes aegypti larvae under starvation conditions. PLoS Negl Trop Dis. 2016;10:e0004320

27. Alphey L, McKemey A, Nimmo D, Neira Oviedo M, Lacroix R, Matzen K, et al. Genetic control of Aedes mosquitoes. Pathog Glob Health. 2013;107:170-9.

28. Marshall JM. The impact of dissociation on transposon-mediated disease control strategies. Genetics. 2008;178:1673-82.

29. Carrington LB, Tran BCN, Le NTH, Luong TTH, Nguyen TT, Nguyen PT, et al. Field- and clinically derived estimates of Wolbachia-mediated blocking of dengue virus transmission potential in Aedes aegypti mosquitoes. Proc Natl Acad Sci U S A. 2018;115:361-6.

30. Joubert DA, Walker T, Carrington LB, De Bruyne JT, Kien DHT, Hoang NLT, et al. Establishment of a Wolbachia superinfection in Aedes aegypti 
mosquitoes as a potential approach for future resistance management. PLoS Pathog. 2016;12:e1005434.

31. World Mosquito Programme. WMP's mosquito releases take flight. 2018. http://www.eliminatedengue.com/progress/index/view/news/1117. Accessed 13 Nov 2019.

32. International Monetary Fund. World Economic Outlook Database, April 2017 , section 5: Report for Selected Countries and Subjects. https:/www.imf.org/ external/pubs/ft/weo/2018/01/weodata/weorept.aspx?pr.x=43\&pr.y=19\&sy= $2017 \&$ ey $=2017 \& \mathrm{scsm}=1 \& \mathrm{ss} d=1 \&$ sort $=$ country \&ds $=\& \mathrm{br}=1 \& \mathrm{c}=512 \% 2 \mathrm{C} 672 \% 2$ C914\%2C946\%2C612\%2C137\%2C614\%2C546\%2C311\%2C962\%2C213\%2C6 74\%2C911\%2C676\%2C193\%2C548\%2C122\%2C556\%2C912\%2C6. Accessed 23 June 2018.

33. O'Neill SL, Ryan PA, Turley AP, Wilson G, Retzki K, Iturbe-Ormaetxe I, et al. Scaled deployment of Wolbachia to protect the community from Aedes transmitted arboviruses. Gates Open Res. 2018:2:36.

34. Wilastonegoro NN, Kharisma DD, Laksanawati I, Halasa-Rappel YA, Brady OJ, Shepard DS. Cost of dengue illness in Indonesia: from hospital to nonmedical settings. Am J Trop Med Hyg. 2020. in press.

35. Hoffmann AA, Montgomery BL, Popovici J, Iturbe-Ormaetxe I, Johnson PH, Muzzi F, et al. Successful establishment of Wolbachia in Aedes populations to suppress dengue transmission. Nature. 2011;476:454-7.

36. Neumann PJ, Russell LB, Siegel JE, Prosser LA, Krahn M, Gold MR. Using cost-effectiveness analysis in health and medicine: experiences since the original panel. In: Neumann PJ, Sanders GD, Russell LB, Siegel JE, Ganiats TG, editors. Cost-effectiveness in health and medicine. 2nd editio. Oxford University Press; 2017. p. 1-37.

37. WorldPop. Indonesia 100m population. 2018. http://www.worldpop.org.uk/ data/summary/?doi=10.5258/SOTON/WP00114. Accessed 21 Dec 2018.

38. Hoffmann AA, Ross PA, Rašić G. Wolbachia strains for disease control: ecological and evolutionary considerations. Evol Appl. 2015;8:751-68.

39. Huber K, Le Loan L, Hoang TH, Ravel S, Rodhain F, Failloux AB. Genetic differentiation of the dengue vector, Aedes aegypti (Ho Chi Minh City, Vietnam) using microsatellite markers. Mol Ecol. 2002;11:1629-35.

40. Suaya JA, Shepard DS, Chang M-S, Caram M, Hoyer S, Socheat D, et al. Costeffectiveness of annual targeted larviciding campaigns in Cambodia against the dengue vector Aedes aegypti. Tropical Med Int Health. 2007:12:1026-36.

41. Luz PM, Vanni T, Medlock J, Paltiel AD, Galvani AP. Dengue vector control strategies in an urban setting: an economic modelling assessment. Lancet. 2011;377:1673-80

42. Mendoza-Cano O, Hernandez-Suarez CM, Trujillo X, Ochoa Diaz-Lopez H, Lugo-Radillo A, Espinoza-Gomez F, et al. Cost-effectiveness of the strategies to reduce the incidence of dengue in Colima, México. Int J Environ Res Public Health. 2017;14:890.

43. Liyanage P, Rocklöv J, Tissera H, Palihawadana P, Wilder-Smith A, Tozan Y Evaluation of intensified dengue control measures with interrupted time series analysis in the Panadura Medical Officer of Health division in Sri Lanka: a case study and cost-effectiveness analysis. Lancet Planet Heal. 2019:3:e211-8.

44. de Soárez PC, Silva AB, Randi BA, Azevedo LM, Novaes HMD, Sartori AMC. Systematic review of health economic evaluation studies of dengue vaccines. Vaccine. 2019;37:2298-310.

45. Brady OJ, Slater HC, Pemberton-Ross P, Wenger E, Maude RJ, Ghani AC, et al. Role of mass drug administration in elimination of Plasmodium falciparum malaria: a consensus modelling study. Lancet Glob Heal. 2017;5:e680-7.

46. Yakob L, Funk S, Camacho A, Brady O, Edmunds WJ. Aedes aegypti control through modernized, integrated vector management. PLoS Curr. 2017. https://doi.org/10.1371/currents.outbreaks.45deb8e03a438c4d088afb4.

47. WHO. A Toolkit for national dengue burden estimation. Geneva: World Health Organization, Department of Control of Neglected Tropical Diseases. 2018. https://www.who.int/denguecontrol/resources/WHO-CDS-NTD-VEM-2 018.05/en/. Accessed 23 May 2020.

48. Harapan H, Michie A, Mudatsir M, Nusa R, Yohan B, Wagner AL, et al. Chikungunya virus infection in Indonesia: a systematic review and evolutionary analysis. BMC Infect Dis. 2019;19:243.

49. Drummond M, Barbieri M, Cook J, Glick HA, Lis J, Malik F, et al. Transferability of economic evaluations across jurisdictions: ISPOR good research practices task force report. Value Heal. 2009;12:409-18.

50. Kolopack PA, Parsons JA, Lavery JV. What makes community engagement effective?: lessons from the eliminate dengue program in Queensland Australia. PLoS Negl Trop Dis. 2015;9:e0003713.

\section{Publisher's Note}

Springer Nature remains neutral with regard to jurisdictional claims in published maps and institutional affiliations.

\section{Ready to submit your research? Choose BMC and benefit from:}

- fast, convenient online submission

- thorough peer review by experienced researchers in your field

- rapid publication on acceptance

- support for research data, including large and complex data types

- gold Open Access which fosters wider collaboration and increased citations

- maximum visibility for your research: over $100 \mathrm{M}$ website views per year

At BMC, research is always in progress.

Learn more biomedcentral.com/submissions 